\section{Welcome to Volume 6 of International Journal of Endocrine Oncology}

Jennifer Straiton*,1

${ }^{1}$ Future Science Group, Unitec House, 2 Albert Place, London, N3 1QB, UK

*Author for correspondence: j.straiton@future-science.com

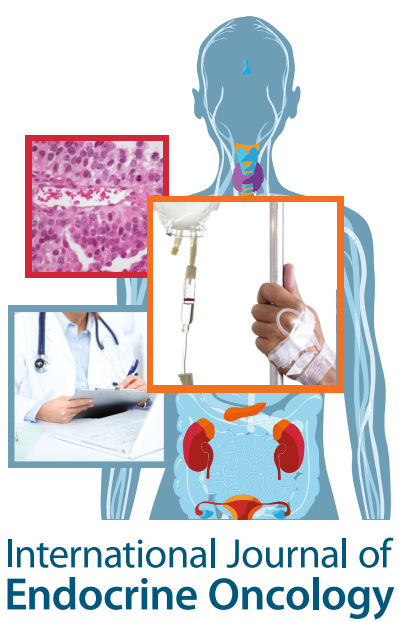

First draft submitted: 11 December 2018; Accepted for publication: 12 December 2018; Published online: 12 February 2019

As the new Editor for International Journal of Endocrine Oncology, it is with great excitement that I introduce the first issue of Volume 6. 2019 has lots of interesting things to be excited about; new projects, new ideas and, of course, more excellent content from all of our authors. The start of our new Journal Watch series will help to broaden the range of topics we are able to publish, increasing our coverage of the latest research in the field.

However, before we start this new period, I would like to look back over the past year and our highlights from 2018.

\section{Content highlights of 2018}

The standard of content that we publish has remained high. This is due to both our authors and reviewers who utilize our peer review and revisions policy to ensure all work is at its best. We have received a variety of article types from an international range of authors, each piece providing novel, interesting and exciting developments in the field of endocrine oncology management.

Our most-read article of 2018 also happens to be our most-read article of all time. The original research study from Jasmine Shell and the team from the National Cancer Institute (MD, USA) investigated the use of 68-gallium DOTATATE PET-CT imaging in symptomatic patients with suspected neuroendocrine tumors though negative anatomic imaging [1]. Their study suggested the validity of using this imaging technique for determining a diagnosis in difficult cases as well as the benefit of utilizing this information to guide future treatment.

Another 2018 article hitting the most-read list is a review from Kristin Long and Rebecca Sippel, from the University of Wisconsin (WI, USA), that discussed treatments for parathyroid carcinoma, both current and future [2]. With surgery currently being the most common method of treatment, the authors advised on the importance of collaborative research to improve early recognition methods as well as to identify novel adjuvant therapies.

An editorial authored by Martyn Caplin of University College London (London, UK) introduced lutetium $\left({ }^{177} \mathrm{Lu}\right)$ oxodotreotide following its recent approval in Europe for the treatment of gastroenteropancreatic neuroendocrine tumors [3]. This approval has provided a new therapy option for these traditionally difficult-to-treat tumors and is suggested to improve quality of life, showing a reduced risk of progression or death relative to previously used treatments.

\section{Editorial Board}

To our Editorial Board, we thank you for your continued input, be it in an ambassadorial, advisory or authorship role. Led by our Senior Editors Electron Kebebew and Karel Pacak (both of the National Cancer Institute, MD, USA), our international board provides valuable assistance and advice that facilitates the publication process; we look forward to working together in the coming year.

On this note, if you are interested in joining our advisory board or wish to provide feedback or suggestions for the journal, please do not hesitate to get in touch; we value any and all input that can contribute to the growth and development of the journal.

\section{Article outreach}

To help further spread the work we publish, we continue to utilize the power of social media and share new work through platforms such as Twitter to ensure articles can be shared with the largest possible audience; if you
Future 8 Medicine 
do not already, we welcome you to follow us on Twitter (@fsgije). In using social media it is our aim to reach all relevant stakeholders in the field of endocrine oncology including researchers, clinicians, charities, patients, academics/educators and patient advocates, just to mention a few.

Our partnership with the site Oncology Central [4] continues, giving authors the opportunity to put their work on the Oncology Central website and be seen by its wide readership base. Registration to Oncology Central is free and allows you to keep up to date with the latest developments in cancer via unparalleled free access to the latest news, opinion, peer-reviewed journal articles, multimedia and exclusive content.

\section{Conclusion}

Our readers remain central to the success of our journal and we welcome any feedback. Please do not hesitate to contact us with any suggestions for what you would like to see featured or any article proposals of your own. We welcome a wide range of unsolicited article proposals so please do get in touch for more information.

I would like to finish by once again thanking all of the authors and reviewers who helped to make Volume 5 possible; we hope to continue to build on this success and look forward to another great year.

\section{Financial \& competing interests disclosure}

J Straiton is an employee of Future Science Ltd. The author has no other relevant affiliations or financial involvement with any organization or entity with a financial interest in or financial conflict with the subject matter or materials discussed in the manuscript apart from those disclosed.

No writing assistance was utilized in the production of this manuscript.

Open access

This work is licensed under the Creative Commons Attribution 4.0 License. To view a copy of this license, visit http://creativecomm ons.org/licenses/by/4.0/

\section{References}

1. Shell J, Keutgen XM, Millo C et al. 68-Gallium DOTATATE scanning in symptomatic patients with negative anatomic imaging but suspected neuroendocrine tumor. Int. J. Endocr. Oncol. 5(1), IJE04 (2018).

2. Long KL, Sippel RS. Current and future treatments for parathyroid carcinoma. Int. J. Endocr. Oncol. 5(1), IJE06 (2018).

3. Caplin M. The recent European approval of lutetium $\left({ }^{177} \mathrm{Lu}\right)$ oxodotreotide increases treatment options for gastroenteropancreatic neuroendocrine tumors. Int. J. Endocr. Oncol. 5(2), IJE09 (2018).

4. Oncology Central. www.oncology-central.com 